\title{
Cataract Surgery Outcomes in New South Wales, Australia
}

\author{
Rahul Dubey, Kenny Chan, Somsak Lertsumitkul, John Grigg, Peter Joseph McCluskey \\ Sydney Hospital/Sydney Eye Hospital, Sydney, Australia
}

\begin{abstract}
Aim: To prospectively assess the visual acuity outcomes of phacoemulsification surgery in 2 tertiary referral hospitals over an 8-year period, and to compare the outcomes achieved by ophthalmology consultants and registrars in routine clinical practice to assess the appropriateness of patient allocation.

Methods: This prospective/retrospective case series of phacoemulsification surgery recruited patients from 1 July 2000 to 30 Dec 2008. Patients underwent detailed ophthalmic examination before and after surgery. Phacoemulsification and insertion of intraocular lens was performed by consultants and senior and junior registrars, who were allocated by the treating consultant. Postoperative review was conducted 1 day, 1 week, 1 month, and 3 months after surgery.

Results: Of the 1812 cases, 1596 (88.1\%) were complication free. The mean postoperative visual acuity was 0.17 LogMAR (6/9 Snellen equivalent), with 1630 cases (90.0\%) achieving 0.30 LogMAR (6/12) or better. Consultants, and senior and junior registrars all achieved similar postoperative visual acuities of 0.15 to 0.17 $\operatorname{LogMAR}(p=0.5)$. There was a significantly different rate of vitreous loss between the 3 groups $(p=0.002)$, with consultants at 2.9\% (9/309), senior registrars at 1.9\% (15/804) and junior registrars at 5.3\% (37/699). Conclusions: The visual acuity outcomes and complication rates confirm that quality care is being delivered to patients. The different complication rates between consultants and registrars reflect consultants allocating themselves more complicated cases and the training of junior registrars. The similar postoperative visual acuities achieved showed that allocation of patients among consultants and registrars was appropriate and good visual acuity outcomes were delivered to all patients.
\end{abstract}

Key words: Aged, Clinical competence/standards, Internship and residency/statistics and numerical data,
Intraoperative complications, Ophthalmology/education, Phacoemulsification

Asian J Ophthalmol. 2011;12:124-9.

\section{Introduction}

Cataract is one of the most common causes of visual impairment in the world. ${ }^{1}$ It has been estimated that, in 2009, 1.68 million Australians aged 55 years or older had serious cataract in at least 1 eye, a prevalence of $31.1 \%{ }^{2}$ With the ageing of the population, it is projected that by 2021, the number of Australians with cataracts will rise to 2.74 million. ${ }^{3}$ Impaired vision has been shown to considerably affect quality of life, ${ }^{4,5}$ thus cataracts are a growing health problem for the ageing population.

Cataract surgery is a very successful procedure for improving patients' vision. ${ }^{6-11}$ Cataract surgery techniques and associated technology have improved considerably over the past 70 years, with the current technique being sutureless small-incision phacoemulsification under local anaesthesia as a day patient. ${ }^{12}$ Cataract surgery is now a very safe procedure with excellent outcomes, ${ }^{10,13,14}$

Correspondence: Dr Rahul Dubey, Sydney Eye Hospital, Sydney,

NSW 2000, Australia.

Tel: (61 02) 93827111;

E-mail: drrahuldubey@gmail.com and the threshold for surgery has been gradually lowered..$^{15}$ The public is increasingly educated about the benefits of cataract surgery. The result is a growing demand for cataract surgery, ${ }^{16}$ which is now the most commonly performed surgical procedure in Australia, with more than 197,000 operations performed from July 2008 to June $2009 .{ }^{17}$

Patients also have increasingly high expectations of their outcomes from cataract surgery. Therefore, to ensure that the best quality of care is being delivered to patients, this large study of consecutive phacoemulsification surgeries was performed to investigate whether the complication rates and visual acuity outcomes from phacoemulsification and insertion of intraocular lens (IOL) at 2 teaching hospitals in New South Wales, Australia, are comparable to similar centres internationally.

With patients expecting excellent surgical outcomes from cataract surgery, there can be a perception that the outcome is better when the surgeon is more experienced. ${ }^{14}$ Patients may believe that they could have inferior outcomes if their procedures are performed by a trainee. A number of previous studies have 
investigated the complication rates and visual acuity outcomes of cataract surgery performed by trainees. ${ }^{18-20}$ However, this is the first study to directly compare registrars (trainees) with consultants in routine clinical practice, thus enabling assessment of the appropriateness of patient allocation.

\section{Methods}

This prospective/retrospective case series was performed at 2 hospitals in Sydney, with a catchment population of 4.4 million. The population is reasonably representative of patients presenting with cataracts to the Australian public health service. However, there was a high proportion of migrants and people of poor socioeconomic background given that the study was conducted in the publicly funded healthcare system.

After ethics approval was obtained from the Sydney South West Area Health Service and Sydney South East IIlawarra Area Health Service, patients' data were collected prospectively and retrospectively over 8 years. 1348 patients who underwent phacoemulsification and insertion of an IOL between 1 July 2000 and 30th June 2005, were recruited prospectively and 438 patients were recruited retrospectively between 1st July 2007 and 31st December 2007. Patients were excluded from the study if there was an accompanying secondary procedure (such as trabeculectomy) or if the patient had planned aphakia as an outcome. Procedures that began as phacoemulsification, but were subsequently converted to extracapsular cataract extraction (ECCE) due to complications were not excluded.

During the study period, 2054 phacoemulsifications were performed in 1786 patients by 15 consultants, 12 senior registrars, and 27 junior registrars, for whom complete follow-up data were available for 1812 cases $(88.2 \%)$.

All patients underwent phacoemulsification surgery at Liverpool Hospital and Sydney Eye Hospital. The specific surgical technique was at the discretion of the operating surgeon, with both divide and conquer and phacochop techniques being used. The procedure was performed by an ophthalmology consultant, or a senior or junior registrar under supervision. Patients were allocated a primary surgeon by the consultants according to their clinical judgement. At the end of the procedure the operating surgeon was required to record any intraoperative complications that may have occurred.

Postoperatively, patients were reviewed by the same surgical team on day 1 , then at 1 week, 1 month, and 3 months, and subsequently as necessary. A standardised postoperative assessment form was completed that recorded best-corrected visual acuity (BCVA) at 3 months and any postoperative complications. Patients who had complicated surgery were followed up for up to 5 years.
Visual acuities measured by Snellen charts under standard illumination conditions were converted into logarithm of minimum angle of resolution (LogMAR) for analysis. ${ }^{21}$ Counting fingers vision was converted to $6 / 600$ and hand movements to $6 / 6000 .{ }^{21}$ Patients with no light perception or light perception only were excluded from the analysis as these were detection of stimuli and not visual acuity measurements. ${ }^{21}$

Statistical analyses were performed by using the Statistical Package for the Social Sciences (SPSS Inc, Chicago, USA) with significance defined as $p<0.05$.

\section{Results}

There were 1812 cases of phacoemulsification and insertion of IOL with complete data. The average age of the patients was 74.7 years (SD, 8.7 years; range, 10 to 96 years). The sex ratio was fairly even with slightly more women $(n=953 ; 52.6 \%)$. 859 procedures $(47.4 \%)$ were performed in left eyes.

The rates of intra- and postoperative complications are summarised in Table 1. Overall, 1596 cases (88.1\%) were complication free. The most common intraoperative complication was posterior capsular (PC) tear, with or without vitreous loss in 62 cases (3.4\%). The next most common complication was anterior capsular tear in 37 cases $(2.0 \%)$. Dropped nucleus occurred in 5 cases $(0.3 \%)$ and 13 cases $(0.7 \%)$ were converted to ECCE.

Postoperatively, the most common complications were posterior capsular opacification (PCO) requiring YAG laser treatment in 48 cases $(2.6 \%)$, and iris prolapse in 29 cases (1.6\%). Cystoid macular oedema occurred in 12 cases $(0.7 \%)$, microbial endophthalmitis in 1 case $(0.1 \%)$, and wound leak in 3 cases $(0.2 \%)$.

The average preoperative BCVA was 0.73 LogMAR $(6 / 30$ Snellen equivalent) Postoperatively, the patients' average BCVA

Table 1. Intra- and postoperative complication rates $(n=1812)$.

\begin{tabular}{lc}
\hline Complication & Number of cases (\%) \\
\hline Intraoperative complications & \\
Posterior capsular tear \pm vitreous loss & $62(3.4)$ \\
Anterior capsular tear & $37(2.0)$ \\
Iris prolapse & $29(1.6)$ \\
Descemet's flap & $15(0.8)$ \\
Dropped nucleus & $5(0.3)$ \\
Iris injury & $4(0.2)$ \\
Postoperative complications & \\
Posterior capsular opacification & $48(2.6)$ \\
Cystoid macular oedema & $12(0.7)$ \\
Corneal oedema & $9(0.5)$ \\
Intraocular pressure spike & $3(0.2)$ \\
Intraocular lens dislocation & $3(0.2)$ \\
Wound leak & $3(0.2)$ \\
Retinal detachment & $3(0.2)$ \\
Microbial endophthalmitis & $1(0.1)$ \\
\hline
\end{tabular}


was 0.17 LogMAR (6/8.87). This represented an average BCVA gain of -0.56 LogMAR. Of the 1812 cases performed, 1667 (92.0\%) achieved 0.30 LogMAR (6/12) or better. The pre- and postoperative BCVAs are shown in Table 2.

Of the 1812 cases of cataract surgery performed in the study period, 309 (17.1\%) were performed by consultants, $804(44.4 \%)$ by senior registrars, and 699 (38.6\%) by junior registrars. The baseline characteristics of the 3 groups of patients are shown in Table 2. There were no statistically significant differences among the 3 groups in terms of patients' sex, side of the surgery, and age.

There were statistically significant differences among the 3 groups' preoperative BCVAs $(p=0.02)$. Consultants had patients with the worst preoperative BCVAs, with a mean of 0.83 LogMAR (6/40) Junior registrars had patients with the best preoperative BCVAs, with a mean of 0.69 LogMAR (6/30), Senior registrars had patients with BCVAs that were in between the other 2 groups, with a mean of 0.73 LogMAR (6/35). Follow-up individual comparisons showed that statistical significance was achieved only between consultants and junior registrars $(p=0.02)$.

There were statistically significant differences in the rate of complication-free phacoemulsifications $(p=0.001)$. The proportion of cataract surgeries that were complication free was 257/309 (83.2\%) for consultants, $738 / 804$ (91.8\%) for senior registrars, and $601 / 699$ (86.0\%) for junior registrars (Table 3).

PC tear was the only complication that achieved statistically significant differences among the 3 groups $(p=0.002)$. Consultants had 9 cases $(2.9 \%)$ of vitreous loss, senior registrars had 15 cases $(1.9 \%)$, and junior registrars had 37 cases $(5.3 \%)$. There were no statistical differences among the 3 groups for all other intraoperative and postoperative complications.

The 3 groups postoperative BCVAs (Table 2) showed no statistical difference $(p=0.5)$, all achieving BCVAs of 0.15 to 0.18 LogMAR (6/9). The difference in gain in BCVA is a reflection of the different preoperative BCVAs and uniform postoperative BCVAs.

Table 2. Comparison of patients operated on by consultants, and senior and junior registrars $(n=1812)$.

\begin{tabular}{|c|c|c|c|c|}
\hline & Consultant & Senior registrar & Junior registrar & p Value \\
\hline Number of patients (\%) & $309(17.1)$ & $804(44.4)$ & $699(38.6)$ & \\
\hline Number of women (\%) & $163(52.8)$ & $434(54.0)$ & $356(51.0)$ & $0.61^{\star}$ \\
\hline Number of left eyes (\%) & $146(47.2)$ & $370(46.0)$ & $343(49.1)$ & $0.76^{*}$ \\
\hline Age (SD) [years] & $72.9(9.8)$ & $71.5(9.6)$ & $69.5(9.2)$ & $0.13^{*}$ \\
\hline Mean preoperative BCVA (95\% confidence interval) [logMAR] & $0.83(0.74-0.89)$ & $0.73(0.68-0.78)$ & $0.69(0.62-0.72)$ & $0.02^{\dagger}$ \\
\hline Mean postoperative BCVA (95\% confidence interval) [logMAR] & $0.17(0.13-0.19)$ & $0.15(0.13-0.16)$ & $0.18(0.16-0.19)$ & $0.50^{\dagger}$ \\
\hline
\end{tabular}

* Compared using chi-squared test.

+ Compared using analysis of variance.

Abbreviation: BCVA = best-corrected visual acuity.

Table 3. Comparison of complication rates among consultants, and senior and junior registrars $(n=1812)$.

\begin{tabular}{|c|c|c|c|c|}
\hline & $\begin{array}{l}\text { Consultant } \\
\text { Number (\%) }\end{array}$ & $\begin{array}{l}\text { Senior registrar } \\
\text { Number (\%) }\end{array}$ & $\begin{array}{l}\text { Junior registrar } \\
\text { Number (\%) }\end{array}$ & p Value \\
\hline Number of operations & 309 & 804 & 699 & \\
\hline No complication & 257 (83.2) & $738(91.8)$ & $601(85.9)$ & $0.001^{*}$ \\
\hline Intraoperative complications & $35(11.3)$ & $53(6.6)$ & $75(10.7)$ & \\
\hline Posterior capsular tear & $9(2.9)$ & $15(1.9)$ & $37(5.3)$ & $0.002^{*}$ \\
\hline Anterior capsular tear & $12(3.9)$ & $14(1.7)$ & $13(1.9)$ & $0.35^{\star}$ \\
\hline Iris prolapse & $9(2.9)$ & $12(1.5)$ & $12(1.7)$ & $0.30^{*}$ \\
\hline Descemet's flap & $3(01.0)$ & $9(1.1)$ & $4(0.6)$ & $0.66^{*}$ \\
\hline Iris injury & $2(0.7)$ & $0(0)$ & $3(0.4)$ & $0.06^{*}$ \\
\hline Dropped nucleus & $0(0)$ & $3(0.3)$ & $6(0.8)$ & $0.53^{*}$ \\
\hline Postoperative complications & $18(5.8)$ & $21(2.6)$ & $43(6.2)$ & \\
\hline Posterior capsular opacification & $11(3.6)$ & $15(1.9)$ & $22(3.1)$ & $0.27^{\star}$ \\
\hline Corneal oedema & $0(0)$ & $2(0.2)$ & $7(1.0)$ & $0.08^{\star}$ \\
\hline Cystoid macular oedema & $4(1.3)$ & $3(0.3)$ & $5(0.9)$ & $0.92^{*}$ \\
\hline Intraocular pressure spike & $1(0.3)$ & $0(0)$ & $2(0.3)$ & $0.24^{\star}$ \\
\hline Intraocular lens dislocation & $0(0)$ & $1(0.2)$ & $2(0.3)$ & $0.83^{*}$ \\
\hline Wound leak & $0(0)$ & $0(0)$ & $3(0.4)$ & $0.19^{\star}$ \\
\hline Microbial endophthalmitis & $1(0.3)$ & $0(0)$ & $0(0)$ & $0.06^{*}$ \\
\hline Retinal detachment & $1(0.3)$ & $0(0)$ & $2(0.3)$ & $0.06^{*}$ \\
\hline
\end{tabular}

${ }^{*}$ Compared using Kruskal-Wallis test 
Of the 216 cases that had either intra- or postoperative complications, $203(94.0 \%)$ had longer follow-up of up to 5 years (mean, 18 months). These patients' mean long-term BCVA of $0.24 \operatorname{LogMAR}(6 / 10)$ was worse than that for the group with no complications of $0.17 \operatorname{LogMAR}(6 / 9)$, but there was no significant difference among the 3 groups $(p=0.59)$. The 3 groups also showed no significant differences in their chances of achieving 0.30 LogMAR $(6 / 12)$ or better $(p=0.42)$, development of subsequent complications $(p=0.23)$, and need for further surgery $(p=0.81)$.

\section{Discussion}

This prospective observational study aimed to assess the outcomes of cataract surgery at Liverpool Hospital and Sydney Eye Hospital over 7 years. Intraoperative complications rates in 2 tertiary centres in Sydney, Australia, were found to be similar to other centres internationally. PC tear with or without vitreous loss occurred in $3.4 \%$ of cases. This is comparable to the range of $1.8 \%$ to $9.9 \%$ reported in other centres. ${ }^{11,22,23}$ The rate of dropped nucleus was also similar to those in New Zealand $(0.2 \%$ vs $0.8 \%),{ }^{11}$ but the small number of cases made additional comparison difficult.

Postoperative complication rates in this study were generally lower than expected. For example, the rate of cystoid macular oedema, at $0.6 \%$, is lower than the $2.0 \%$ to $4.6 \%$ rate reported in published studies. ${ }^{11,24,25}$ The rate of microbial endophthalmitis in this study was $0.1 \%$, which is also lower than the $0.265 \%$ rate found in a recent systematic review. ${ }^{26}$ The retinal detachment rate of $0.1 \%$ is lower than the reported rate of $0.2 \%$ to $3.6 \% .^{27,28}$ Similarly, the rate of PCO $(2.6 \%)$ is lower than the $18 \%$ to $50 \%$ found in patients who are followed up for up to 5 years. ${ }^{28}$ The lower rates of postoperative complications found in this study are most likely to be due to the short follow-up of 3 months, meaning that late complications such as PCO might be missed.

Ninety percent of patients achieved a postoperative BCVA of 0.30 LogMAR (6/12) or better. This is similar to the $84 \%$ to $90 \%$ rate reported in numerous studies. ${ }^{7,10,11,19,29-31}$ The mean postoperative
BCVA of 0.17 LogMAR (6/9) is also similar to those found in Denmark, the USA, ${ }^{32}$ and New Zealand (0.1 LogMAR [6/7.5]). ${ }^{11}$

This study has shown that phacoemulsification surgery performed in Sydney, Australia, achieved visual acuity outcomes and intraoperative complication rates similar to those found in many centres internationally, and results similar to the world's best practice.

This is the first study to prospectively, as well as retrospectively, compare the outcomes of phacoemulsification surgery performed by ophthalmology consultants and trainees in routine clinical practice. Previously published studies have largely been retrospective, and assessed trainees in isolation, with a mixture of ECCEs and phacoemulsifications (Table 4). ${ }^{18-20,24,25,33,34}$ This study is unique in comparing phacoemulsification outcomes in patients who have been allocated according to the consultant ophthalmologist's clinical judgement, thus enabling assessment of the appropriateness of this allocation process. Consequently, the patients in this study were not randomised. The 3 groups of patients had significantly different preoperative BCVAs. Consultants operated on patients with the worst preoperative BCVAs, senior registrars operated on those with intermediate BCVAs, and junior registrars operated on those with the best preoperative BCVAs. The likely explanation for this difference is that consultants allocated themselves patients with more complicated cataracts, for example those with ocular comorbidities or more advanced cataracts, and worse preoperative visual acuity, whereas junior registrars were given more straightforward cases appropriate to their stage of surgical training.

In terms of intraoperative complications, senior registrars had the lowest PC tear rate at $1.9 \%$, consultants were second best at $3.0 \%$, and junior registrars worst at $5.3 \%$. The rate achieved by junior registrars is identical to the $5.3 \%$ to $5.4 \%$ found in the UK and New Zealand. ${ }^{11,22}$

It is expected that junior registrars will have a higher complication rate as they learn the surgical technique for cataract surgery. The likely reason for the high complication rates for

Table 4. Studies assessing cataract surgeries performed by ophthalmology trainees.

\begin{tabular}{|c|c|c|c|c|}
\hline Study & Phacoemulsification (\%) & Prospective study & $\begin{array}{c}\text { Comparison of consultants } \\
\text { and trainees }\end{array}$ & Number of patients \\
\hline Straatsma et al, ${ }^{19} 1983$ & 0 & Yes & Yes & 234 \\
\hline Cruz et al, ${ }^{20} 1992$ & 100 & No & No & 181 \\
\hline Smith and Seiff, ${ }^{25} 1997$ & 56 & No & No & 218 \\
\hline Tarbet et al, ${ }^{18} 1995$ & 100 & No & No & 300 \\
\hline Blomquist and Rugwani, ${ }^{33} 2002$ & 87 & No & No & 63 \\
\hline Current & 100 & Yes & Yes & 1366 \\
\hline
\end{tabular}


consultants is that they operated on the more difficult cases. It is also common practice in our institutions that some of the cases started by registrars that involve an intraoperative complication are subsequently taken over by the supervising consultant and thus recorded as consultant data points. There was no difference among the 3 groups in their rates of postoperative complications. Some of the complications were rare and thus difficult to compare.

The longer term follow-up data of patients with complications shows that the equivalence in outcome among the 3 groups was maintained over the longer term. There was a trend for consultant cases to have a higher chance of developing subsequent complications (21.5\%); they also had a higher chance of achieving 0.30 LogMAR acuity (6/12) or better (89.4\%). However there were no statistically significant differences among the 3 groups.

This study has shown that, despite the differences in complication rates, there was no difference among the 3 groups in their postoperative BCVAs. All 3 groups achieved remarkably homogenous postoperative BCVAs of approximately 0.17 LogMAR (6/8.87). This finding supports the conclusion that the routine clinical practice of allocating patients based on the clinical judgement of consultants has appropriately allocated patients to the 3 groups of surgeons, resulting in all patients receiving a similarly good visual acuity outcome.

This study has some weaknesses. By design, the data on postoperative complications is limited. There may have been underreporting of postoperative complications due to reporting bias. This is in contrast to the intraoperative complication rates, which were reliably recorded contemporaneously in the operating theatre thus reflecting the true intraoperative complication rates.

The lack of patient randomisation among the 3 groups may be seen as a weakness, but is, in fact, a strength of the study, enabling assessment of routine clinical practice. A study with randomisation would have compared the surgeons' skill levels but lost the power to draw conclusions regarding normal clinical practice in a teaching hospital.

Our data consistently showed that consultants were more frequently self-allocated patients with ocular comorbidities such as pseudoexfoliation, zonular dehiscence, small pupil, or diabetic retinopathy. It has been shown in that ocular comorbidities significantly affect patients' chances of achieving 0.30 LogMAR $(6 / 12)$ or better postoperatively. When eyes with ocular comorbidities were excluded from studies, the percent of cases achieving postoperative 0.30 LogMAR (6/12) or better typically rises to $95 \%$ from around $85 \%$ to $90 \%{ }^{10,11,25}$

With the ageing of the population, the gradual lowering of the threshold for cataract surgery, and the high expectations of patients, it is critical that a high standard is maintained when performing phacoemulsification and insertion of IOLs. This study shows that over 7 years, visual acuity outcomes and complication rates similar to the world's best practice have been achieved.

Patients considering cataract surgery may believe that their surgical outcome will be better if their procedures are performed by a more experienced surgeon. This is of particular concern to patients presenting to a public hospital clinic. This prospective case series has shown that remarkably uniform visual acuity outcomes were achieved by both consultants and registrars. There was a significant difference in their complication rates, which reflects the more complicated procedures allocated to consultants, and the process of learning by the junior registrars. Despite this, the most significant conclusion drawn from this study is that patients awaiting cataract surgery in New South Wales can have confidence in being allocated an appropriate surgeon and will achieve equally good visual acuity outcomes. It will be beneficial to conduct similar studies at other teaching hospitals to assess the universality of this finding.

\section{Acknowledgements}

We would like to sincerely thank Dr Ute Vollmer-Conna for assistance with statistical analysis and Ms Leeanne Gardner for assistance with the maintenance of the cataract surgery database.

\section{References}

1. Attebo K, Mitchell $P$, Smith W. Visual acuity and the causes of visual loss in Australia. The Blue Mountains Eye Study. Ophthalmology. 1996;103:357-64.

2. Access Economics. Cataract treatment in Australia. 29 Sep 2009 Available from: www.accesseconomics.com.au Accessed 20 April 2011.

3. Rochtchina E, Mukesh BN, Wang JJ, McCarty CA, Taylor HR, Mitchell P. Projected prevalence of age-related cataract and cataract surgery in Australia for the years 2001 and 2021: pooled data from two population-based surveys. Clin Exp Ophthalmol. 2003;31: 233-6.

4. Chia EM, Mitchell P, Rochtchina E, Foran S, Wang JJ. Unilateral visual impairment and health related quality of life: the Blue Mountains Eye Study. Br J Ophthalmol. 2003;87:392-5.

5. Chia EM, Wang JJ, Rochtchina E, Smith W, Cumming RR, Mitchell P. Impact of bilateral visual impairment on health-related quality of life: the Blue Mountains Eye Study. Invest Ophthalmol Vis Sci. 2004;45:71-6.

6. Lundstrom M, Barry P, Leite E, Seward H, Stenevi U. 1998 European Cataract Outcome Study: report from the European Cataract Outcome Study Group. J Cataract Refract Surg. 2001;27: 1176-84.

7. Lundstrom M, Stenevi U, Thorburn W. The Swedish National Cataract Register: a 9-year review. Acta Ophthalmol Scand. 2002;80:248-57.

8. Desai P, Minassian DC, Reidy A. National cataract surgery survey 1997-8: a report of the results of the clinical outcomes. $\mathrm{Br} J$ Ophthalmol. 1999;83:1336-40.

9. Norregaard JC, Bernth-Petersen P, Alonso J, Andersen TF Anderson GF. Visual functional outcomes of cataract surgery in the United States, Canada, Denmark, and Spain: report of the International Cataract Surgery Outcomes Study. J Cataract Refract Surg. 
2003;29:2135-42.

10. Powe NR, Schein OD, Gieser SC, et al. Synthesis of the literature on visual acuity and complications following cataract extraction with intraocular lens implantation. Cataract Patient Outcome Research Team. Arch Ophthalmol. 1994;112:239-52.

11. Riley AF, Malik TY, Grupcheva CN, Fisk MJ, Craig JP, McGhee CN. The Auckland cataract study: co-morbidity, surgical techniques, and clinical outcomes in a public hospital service. $\mathrm{Br} \mathrm{J}$ Ophthalmol. 2002;86:185-90.

12. Linebarger EJ, Hardten DR, Shah GK, Lindstrom RL. Phacoemulsification and modern cataract surgery. Surv Ophthalmol. 1999;44: 123-47.

13. Javitt JC, Brenner MH, Curbow B, Legro MW, Street DA. Outcomes of cataract surgery. Improvement in visual acuity and subjective visual function after surgery in the first, second, and both eyes. Arch Ophthalmol. 1993;111:686-91.

14. Pager CK, McCluskey PJ, Retsas C. Cataract surgery in Australia: a profile of patient-centred outcomes. Clin Exp Ophthalmol. 2004; 32:388-92.

15. McCarty CA, Keeffe JE, Taylor HR. The need for cataract surgery: projections based on lens opacity, visual acuity, and personal concern. Br J Ophthalmol. 1999;83:62-5.

16. Keeffe JE, Taylor HR. Cataract surgery in Australia 1985-94. Aust N Z J Ophthalmol. 1996;24:313-7.

17. Australian Institute of Health and Welfare 2010. Australian hospital statistics 2008-09. Health services series no. 17. Cat. no. HSE 34. Canberra: AlHW. Available from: http://www.aihw.gov.au/ publications/hse/84/11173.pdf Accessed 21 February 2011.

18. Tarbet KJ, Mamalis N, Theurer J, Jones BD, Olson RJ. Complications and results of phacoemulsification performed by residents. $\mathrm{J}$ Cataract Refract Surg. 1995;21:661-5.

19. Straatsma BR, Meyer KT, Bastek JV, Lightfoot DO. Posterior chamber intraocular lens implantation by ophthalmology residents. A prospective study of cataract surgery. Ophthalmology. 1983;90: 327-35.

20. Cruz OA, Wallace GW, Gay CA, Matoba AY, Koch DD. Visual results and complications of phacoemulsification with intraocular lens implantation performed by ophthalmology residents. Ophthalmology. 1992;99:448-52.

21. Holladay JT. Visual acuity measurements. J Cataract Refract Surg.
2004;30:287-90.

22. Ionides A, Minassian D, Tuft S. Visual outcome following posterior capsule rupture during cataract surgery. $\mathrm{Br} \mathrm{J}$ Ophthalmol. 2001;85:222-4.

23. Pingree MF, Crandall AS, Olson RJ. Cataract surgery complications in 1 year at an academic institution. $\mathrm{J}$ Cataract Refract Surg. 1999;25:705-8.

24. Albanis CV, Dwyer MA, Ernest JT. Outcomes of extracapsular cataract extraction and phacoemulsification performed in a university training program. Ophthalmic Surg Lasers. 1998;29:643-648.

25. Smith JH, Seiff SR. Outcomes of cataract surgery by residents at a public county hospital. Am J Ophthalmol. 1997;123:448-54.

26. Taban M, Behrens A, Newcomb RL, et al. Acute endophthalmitis following cataract surgery: a systematic review of the literature. Arch Ophthalmol. 2005;123:613-20.

27. Javitt JC, Vitale S, Canner JK, Krakauer H, McBean AM, Sommer A. National outcomes of cataract extraction. I. Retinal detachment after inpatient surgery. Ophthalmology. 1991;98:895-902.

28. Kohnen T, Wang L, Friedman NJ, Koch DD. Complications of cataract surgery. In: Yanoff M, ed. Ophthalmology. St Louis: Mosby; 2004. p 381-90.

29. Wegener M, Alsbirk PH, Hojgaard-Olsen K. Outcome of 1000 consecutive clinic- and hospital-based cataract surgeries in a Danish county. J Cataract Refract Surg. 1998;24:1152-60.

30. Quillen DA, Phipps SJ. Visual outcomes and incidence of vitreous loss for residents performing phacoemulsification without prior planned extracapsular cataract extraction experience. Am J Ophthalmol. 2003;135:732-3.

31. Randleman JB, Srivastava SK, Aaron MM. Phacoemulsification with topical anesthesia performed by resident surgeons. J Cataract Refract Surg. 2004;30:149-54.

32. Norregaard JC, Hindsberger C, Alonso J, et al. Visual outcomes of cataract surgery in the United States, Canada, Denmark, and Spain. Report from the International Cataract Surgery Outcomes Study. Arch Ophthalmol. 1998;116:1095-100.

33. Blomquist PH, Rugwani RM. Visual outcomes after vitreous loss during cataract surgery performed by residents. J Cataract Refract Surg. 2002;28:847-52.

34. Browning DJ, Cobo LM. Early experience in extracapsular cataract surgery by residents. Ophthalmology. 1985;92:1647-53. 